\title{
Paulo Freire e Merleau-Ponty: conexões dialógicas
}

\author{
Paulo Freire and Merleau-Ponty: dialogic connections
}

Paulo Freire y Merleau-Ponty: conexiones dialógicas

\author{
Armando Melo Lisboa ${ }^{1}$; Luiz Augusto Passos ${ }^{2}$ \\ Universidade Federal de Santa Catarina, UFSC, Florianópolis-SC, Brasil \\ Universidade Federal de Mato Grosso, UFMT, Cuiabá-MT, Brasil
}

\begin{abstract}
RESUMO
O ensaio tece diálogo com Paulo Freire e Merleau-Ponty. Ambos possuem uma história de vida de compromissos políticos e engajamento contra políticas mantidas pela dominação do patriarcalismo, racismo, homofobia, genocídio. Tecem uma concepção voltada de natureza concebendo a Terra como útero da existência de tudo, todas e todos. Ambos se contrapõem à disjunção entre espírito-e-matéria. Denunciam a dicotomia perversa de uma essência espiritual, superior, que se autoriza a guerra contra todas as formas materiais concebidas como sombrias, decaídas, perversas, selvagens e destrutivas. Paulo Freire e Merleau-Ponty tomaram como paradigma o corpo e a corporeidade, como lugar originário e primeiro, de onde emerge um pensamento segundo. Estimulam a comunhão e a convivialidade com tudo, todos e todas.
\end{abstract}

Palavras-chave: Dialogicidade. Diversidade. Autonomia. Convivialidade.

\begin{abstract}
The essay weaves dialogue with Paulo Freire and Merleau-Ponty. Both have a life history of political commitments and engagement against policies maintained by the domination of patriarchalism, racism, homophobia, genocide. They weave a conception focused on nature, conceiving the Earth as the womb of the existence of everything, all and everyone. Both are opposed to the disjunction between spirit and matter. They denounce the perverse dichotomy of a spiritual, superior essence, which authorizes war against all material forms conceived as dark, decrepit, perverse, wild and destructive. Paulo Freire and Merleau-Ponty took as their paradigm the body and corporeality, as the original place and first, from where a second thought emerges. Stimulate communion and conviviality with everything, everyone and everyone.
\end{abstract}

Keywords: Dialogicity. Diversity. Autonomy. Conviviality.

\section{RESUMEN}

El ensayo teje un diálogo con Paulo Freire y Merleau-Ponty. Ambos poseen una historia de vida de compromisos políticos y participación contra políticas mantenidas por la dominación del patriarcalismo, racismo, homofobia, genocidio. Realizan una concepción envuelta de naturaleza concibiendo a la Tierra como útero de la existencia de todo, todas y todos. Ambos se contraponen a la desconexión entre espíritu-y-materia. Denuncian la dicotomía perversa de una esencia espiritual, superior, que se autoriza a la guerra contra todas las formas materiales concebidas como sombrías, decaídas, perversas, salvajes y destructivas. Paulo Freire y Merleau-Ponty tomaron como paradigma el cuerpo y la corporeidad, como lugar originario y primero, de donde emerge un pensamiento de acuerdo. Estimulan a la comunión y la convivencia con todo, todos, todas.

Palabras clave: Dialogicidad. Diversidad. Autonomía. Convivialidad.

\footnotetext{
1 Professor Associado I do Departamento de Economia e Relações Internacionais da UFSC. E-mail: amelolisboa@gmail.com. ORCID: http://orcid.org/0000-0003-0841-2299.

${ }^{2}$ Professor permanente no PPGE da UFMT. Coordena o Grupo de Pesquisa Movimentos Sociais e Educação (GPMSE) e o Grupo de Estudos Educação \& Merleau-Ponty (GEMPO). E-mail: passospassos@ gmail.com. ORCID: http://orcid.org/0000-0001-7475-0523.
} 


\section{ENSAIO}

Vendo, o professor, que aquele idoso, do Agreste pernambucano que jamais faltava a uma só reunião, silencioso, o primeiro a chegar e o derradeiro a sair, imensamente curioso, se "aprochegou" e...

- Me diga por que o senhor sempre vem nas reuniões e não falta nunca?

- Vou lhe dizê, é que o sinhô inventa umas palavras prá eu dizer as minhas coisas!

Do coração central da vida, o velho nordestino do agreste de Pernambuco resumia suas coisas em palavras. Na Escritura, Deus também resumia em Palavras. Assim ensinava Paulo Freire, exímio doutor da palavra irreverente, atrevida e gostosa, nunca U-tópica: não tocável, não tangível. Era pra se lambuzar nela. Sua meninice coça a nossa, nunca negando a infância maliciosa, mal humorada e melada de prazer.

Com sua nordestinidade genética, cinzelava o universo inteiro com a palavra estofada de humanismo revolucionário com cheiro de auroras. Muralha pura do agreste. Ir a Freire é peregrinar e, a partir dele é encontrar no corpo de cada mulher e homem um oceano de sentidos, e maresias de um universo cheio de ambiguidades, e danadezas. É achar no mergulho do meu próprio corpo ${ }^{3}$ (MERLEAU-PONTY, 2006), conexão com todos os corpos do universo, não só de seres que são considerados "humanos". Humanas - sentido estrito - são todas criaturas que, advindas de explosão estelar, que perfizeram seus corpos encharcados de limo e húmus do universo, lugar da ciranda da alegria, das perdas e da fraternura ${ }^{4}$.

Ao mergulhar, em nosso corpo, também nele reencontramos todos os corpos outros do universo, reencontramos alteridades que se fazem presentes, engolfadas em nós, formando um uni-pluriverso que perpassa as fagulhas do nosso corpo, mesclando um tecido comum e nos entrelaça com tudo, todos e todas. Onde pudermos ir, já estivemos de alguma forma lá, nada nos será completamente desconhecido. O big-bang subsiste nas nossas memórias ancestrais e emerge, vez ou outra, como um fundo de vitalidade e de vizinhança. "Estrangeiros, ao mesmo tempo, a nós e a este mundo" (CAMUS, 1967), somos - por não ousar ultrapassar padrões inscritos - tomados por uma pseudo-estrangeiricidade. Cada vez que nos tornamos únicos voltamos à nossa universalidade absoluta compartilhada na carne estelar que nos agasalha e recobre o corpo.

O corpo próprio $^{5}$ - Corps propre - (MERLEAU-PONTY, 2006), singular e único - sempre! -, nos devolve uma verdade de que tudo nos é comum a todo o ser: a diversidade do tudo nos habita. Pelo corpo, compartilhamos diferenças - quaisquer exclusões. Trazemos em nós, cheiro de uma história do universo, um oceano de interconexões entre culturas, fazeres, paladares, estesias, sensações que nos acariciam emergindo da universalidade, nossas singularidades, nossa diferença (FREUD, 1950).

Freire, "desaparelhado para quase tudo", não comprometeu sua doçura selvagem. Se cuidou e se guardou humano, sensível de afeto - o humano selvagem, sem demandas

\footnotetext{
3 “Quer se trate do corpo do outro ou de meu próprio corpo, não tenho outro meio de conhecer o corpo humano senão vivê-lo, quer dizer, retomar por minha conta o drama que o transpassa e confundir-me com ele. Portanto, sou meu corpo, exatamente na media em que tenho um saber adquirido e, reciprocamente, meu corpo é como um sujeito natural, como um esboço provisório de meu ser total" (MERLEAUPONTY, 2006, p. 269).

${ }^{4}$ Neologismo composto de fraternidade com ternura. Leonardo Boff abusava desta palavra. BOFF, L. Leonardoboff.com. Disponível em: https://leonardoboff.org/. Acesso em: 11 abr. 2020.

5 “"...] a experiência do corpo próprio opõe-se ao movimento reflexivo que destaca o objeto do sujeito e o sujeito do objeto, e que nos dá apenas o pensamento do corpo ou o corpo em idéia, e não a experiência do corpo ou o corpo em realidade" (MERLEAU-PONTY, 2006, p. 269).
} 
da artificialidade que impõe desejos artificiais, exteriores, como forma de servidão ao consumo desnecessário para a vida, e todas as outras formas de vida com os animais, com as aves, bactérias, plantas, pedras. E, em cada um deles e delas, nos sentiremos acolhidos e acariciados - há que apreender suas linguagens ${ }^{6}$. Como testamento dizia Paulo Freire: "Eu gostaria de ser lembrado como um sujeito que amou profundamente o mundo e as pessoas, os bichos, as árvores, as águas, a vida" (FREIRE, 2005, p. 329) ${ }^{7}$. Amou toda a alteridade, aquilo que ele era e que não era, mas que ao mesmo reconhecia que "estava nelas..." por uma afinidade de sua mundanidade simples. Quando em África, Paulo Freire sentia na pele, se sabia, lá, mais brasileiro e nordestino do que nunca - " [...] rememorando a sua vida, o Recife, [...] foi constatando então que era mais africano do que se sabia e se considerava" (FREIRE, 2006, p. 225). Uma afinidade de todos os seres do mundo com todas as coisas que nos constituem e se pregam em nós. Nunca estamos sós. Tudo nos habita, e a saudade nos faz reconhecer.

Não se pode compreender um Freire quadradinho e feito manequim de gravata e terno. Sua grandeza - humanidade desmesurada - era um libelo à liberdade, à simplicidade, em estar-com! Freire continua esse portal - destituído de porteiras - que convida a entrar na vida, para o essencial dela: a convivência, a comunhão, o acolhimento e a esperança ainda em um mundo dividido e tensivo, mas elogiou a raiva ética, contra as maldades e malfeitores. Disse descaradamente, ao lado do Dom Paulo Evaristo Arns: resumirei - "Como perdoar os opressores se não for feita a compensação dos males produzidos pela injustiça e exploração?" (SEMINÁRIO, 1996). Sempre surpreendente, nunca se sabia exatamente o que viria de sua boca. Ele, além de tudo, de nascença, trazia um olhar enviesado. Esse diferencial, de poder entortar as coisas, tão iguais às formas mais toscas; tal como pessoa que se guardou criança e não foi domada em uma escola nem aceitou a condição do ordenamento ressecado: “[...] ¡niño, rápido, contesta, no pienses!” (MELIÀ, 1972), disse isso, o linguista antropólogo jesuíta Bartomeo Melià, nascido em Porreres (Baleares, Espanha). Esse diferencial, de poder entortar as coisas, tão iguais às formas primaciais, como criatura que guardou na sua doce animalidade, como tesouro. Desistiu da civilização da culpa (FREUD, 1950). Não foi domado em uma escola, diria Bartomeo Melià, que mencionava que os indígenas são produto de artesanato, nós, da linha de montagem da fábrica. Das gentes que não aceitaram ordenamento ressecado que estiola a alma, tanto quanto a fragilidade todo poderosa de não se poder dobrar os Guarani para torná-los cópia de demissão de sua humanidade terreal. Assim dizia Melià no seu poema-canção:

$$
\begin{array}{r}
{[\ldots] \text { felices ustedes }} \\
\text { los a-n-a-l-f-a-b-e-t-o-s } \\
\text { los que no leen siquiera el ABC } \\
\text { los que no fueron acorralados por la civilización } \\
\text { ni marcados con las letras del amo } \\
\text { ni domados en una escuela } \\
\text { los que siempre han logrado pensar salvajemente }
\end{array}
$$

\footnotetext{
${ }^{6}$ Merleau-Ponty descreve nominando como "Ser pré-objetivo: o mundo solipsista” em "O visível e o invisível" (MERLEAU-PONTY, 2009, p.153).

${ }^{7}$ PAULO Freire - Dia do Meio Ambiente - 5 de junho. Publicado pelo canal Instituto Paulo Freire em jun. 2015. 1 vídeo (22 seg.). Disponível em: https://www.youtube.com/watch?v=J170pf5e5No. Acesso em: 11 abr. 2020.

${ }^{8}$ Vejam no link do Seminário "O Simbólico e o Diabólico". É quase no final do Seminário, todo ele imperdível! SEMINÁRIO Internacional "O Simbólico e o Diabólico, Dramas e Tramas, Religião, História e Política”. Teatro da Universidade Católica de São Paulo (TUCA), set. 1996. 1 vídeo (64 min.). Publicado pelo canal TV PUC. Disponível em: https://www.youtube.com/watch?v=Me7yEtvctog. Acesso em: 11 abr. 2020.
} 
y no repiten de memoria como loros en coros

los catecismos del estado de sitio - ¡niño, rápido, contesta, no pienses! (MELIÀ, 1972) ${ }^{9}$.

Não era diferente Melià, do que a mãe de Manoel de Barros dizia de seu filho, todo pantaneiro, todo ribeirinho; profetizando ela dizia de maneira linda, da criança que respirava liberdade de viver intensamente o mundo, com seu corpo, escorado do apoio do olhar terno da mãe, que peregrinava nas profundezas de seu mundo, conferindo-lhe asas.

Manoel de Barros traz também o "Freire" em sua meninice que o próprio Manoel de Barros poeticamente enunciou:

Com o tempo aquele menino que era cismado e esquisito Porque gostava de carregar água na peneira.

[...] O menino aprendeu a usar as palavras. Viu que podia fazer peraltagens com as palavras. E começou a fazer peraltagens.

Foi capaz de interromper o voo de um pássaro botando ponto no final da frase.

Foi capaz de modificar a tarde botando uma chuva nela. O menino fazia prodígios.

Até fez uma pedra dar flor!

A mãe reparava o menino com ternura.

A mãe falou: Meu filho você vai ser poeta. Você vai carregar água na peneira a vida toda. Você vai encher os vazios com as suas peraltagens. E algumas pessoas vão te amar por seus despropósitos. (BARROS, 2010, p. 470) ${ }^{10}$.

Paulo Freire, amparado em Mounier (1973), entendia que o termo "pessoa", em uma de suas acepções no grego, PROSOPON - adquiria um sentido pouco explorado: Mounier que fundava sua etimologia, aquele(a) que se CONTRAPÕE. Mencionava a dificuldade do diálogo na política, pois a palavra PESSOA, dizia do ser único, e que ao pronunciar-se jamais poderia ser calada, silenciada ou proibida. Cada pessoa tem direito a compartilhar como singularidade que era as múltiplas perspectivas e sentidos que a teceriam de jeito incopiável, perspectivando uma visão única da realidade diversa. Nas conflitividades emergentes, o ser pessoa, em seu devir, costurava um escopo mais rico, que abria portas para sentidos convergentes, para erigir uma república expressiva e democrática, ainda que difícil, na festa ruidosa das opiniões.

Merleau-Ponty tinha como realidades fundantes o corpo e a carne, entrelaçados e inseparáveis, cada qual tinha uma natureza única e singular. O primeiro - o corpo - dizia da nossa solidão e singularidade corporal; o segundo da carnalidade - a carne - que nos faz - públicos - todos idênticos a todas as outras criaturas do universo. Portanto, ao mesmo tempo Universais pela CARNE, e ao mesmo tempo singulares pelo CORPO ${ }^{11}$.

A "carne" não é corpo carnal, como nos acostumamos a considerar na nossa cultura dominante, não se refere jamais à carne física ou biológica. A Carnalidade de

\footnotetext{
${ }^{9}$ MELIÀ, B. ¡Ay del que enseña a leer al que no sabe! Acción, Asunción, n. 14, 1972. Disponível em: http://www.mondialisations.org/medias/pdf/Ay-del-que-ensena-a-leer.pdf. Acesso em: 11 abr. 2020.

${ }^{10}$ BARROS, M. O menino que carregava água na peneira. In: BARROS, M. Poesia completa. São Paulo: Leya, 2010. p. 469-470.

${ }^{11}$ Não por alternância, ora um, ora outro, mais por absoluta simultaneidade, imbricada uma na outra no contexto de mundo.
} 
Merleau-Ponty é o vínculo de todas as coisas do universo serem criaturas, feitas no mesmo ato de amor do Pai, que as torna rigorosamente idênticas e iguais. Carne é, menos o princípio material, biológico ou físico, aquilo que nos vincula a um ato amoroso e criador do universo, faz universalmente que sejamos - tudo, todos e todas,criaturas iguais em natureza no universo ${ }^{12}$.

O nosso corpo próprio, singular e único, cuja relação com o mundo jamais será a mesma para qualquer outro corpo próprio no mundo; também em cada criatura a sua forma própria estamos nela e ela em nós. Carne e corpo são contradições que não se separam jamais. Uma complementa a outra. Mantendo a necessária tensão dialética da existência de cada pessoa, no mundo, como um universo dentro de outro. Tensão dialógica, fissão tensiva: todos, todas e tudo somos universais até o fim - e - somos singulares - até o fim.

Freire não olhava uma pessoa como se fosse um ser idêntico pelo fato de ser oprimido - e dentro de uma mesma comunidade, a cada olhar, solene, descobria a diferença única, que dava a cada pessoa um mistério que se apreendido por nós, nos enriquece e nos ensina. Ninguém é igual a ninguém. Quem vê nas pessoas "massa" demonstra a imensa ignorância e prepotência por que o faz ele mesmo retirando-se dessa condição genérica, e fingindo que porta uma diversidade somente dele.

Carne significa afirmar que se para qualquer criatura, seu corpo é um corpo único, singular e próprio, e ele é o primeiro em nós, que precede em muito todo e qualquer conhecimento, e por outro a noção das coisas que temos ${ }^{13}$ (MERLEAU-PONTY, 2006).

Carne, por sua comunhão com o cosmo e todas as criaturas, perfaz um estofo no universo que universaliza a todos e todas por sua criaturidade, com a qual todas as formas de ser se identificam, por pertencerem a uma energia criadora que a todas, todos e tudo, sem qualquer exceção, nos faz rigorosamente universais e os mesmos.

Há um saber que emerge da misturança que somos e, é dele e nele que é possível construir uma perspectiva da natureza viva e mutante cuja complexidade nos encontramos sendo, apenas um exemplar na história inteira do mundo (CHAUÍ, 1981).

Nos apreendemos no mundo, sendo. Mas já éramos, antes mesmo quando ainda não nos apreendíamos. $\mathrm{O}$ mundo nos apreendeu e nos modelou antes mesmo que tivéssemos um conhecimento segundo, distanciado, modelado pelo corpo, e sem consciência de existir. Antecedemos a nós mesmos, pela palavra-carne em erupção no corpo. São as necessidades da nossa animalidade vital (FIRENZE, 2014), medo, sensações, convulsões internas, queimores, suores, ruídos, vozes de carinho e afagos antes das mãos, risinhos de pai e mãe, que apreendem o sentido do prazer e da presença da alteridade que nos toma: verdadeiramente nos precede, como se dormíssemos.

Vivendo em estado de dormência, começa no conflito e no confronto a sede de viver, a débil noção de uma pré-consciência de existir. E, um existir conflitivo, do alter que, em grande parte, suscita nossa resposta. Se desenha então uma fissura - quebra ontológica - que fará uma distância entre o que estamos sendo e vivendo, com as vivências corporais prazerosas ou doídas, que não provocamos. Estamos ainda no útero, povoados pelos próximos, escorados nos vestígios das ebulições arqueológicas e ancestrais. E emerge nosso sistema neurológico rompendo nosso autismo inicial, feito pela luta de viver e sobreviver, em meio ao conjunto de alteridades que nos povoam e

\footnotetext{
${ }^{12}$ E o crime perverso e delinquente da cultura é a incapacidade de conviver com tudo o que é diverso, tem que ser aplainado, exterminado e morto, tanto na cultura, na sexualidade, nas etnias, nas formas de poder pensar etc.

${ }^{13}$ Vídeo de Marilena Chauí nos ensinado Merleau-Ponty, enfatizando a unidade e primacialidade do corpo: https://www.youtube.com/watch?v=dUiI5VWF7m8.
} 
nos tomam por dentro: nascemos dos/com outros(as), e como fagulha, chispa, pela primeira vez, o eu-nós!

Viver e querer viver são também uma disputa, seja por ódio, seja por amor, seja pela presencialidade carinhosa, seja pelo desafio do SER MAIS que nos acompanhará no horizonte ontológico e ético que nos provoca. Nós descobrimos que estamos sendo, e intermináveis (FREIRE, 1983).

Talvez pudéssemos inventar muitos nomes para a emergência da consciência de nossa interminável fissão primeira, feita por um trauma, uma palavra, uma lágrima, um carinho, um sentido de presença de nós em nós, inimitáveis que somos pelo nosso corpo próprio e, nele, o grito $^{14}$. Nele se inscreve também uma perspectiva inédita pela qual, só por ela pode ser visto o mundo que cada um de nós, como seres singulares somos: não teremos senão a distância infinita de querer se ver por dentro, e encontrar a alma gêmea que me mostre a face. Um grito é uma demanda contra a negação, com a falta, contra o que nos foi tirado. É o começo da eticidade, e de fazer-se gente em comunhão.

A busca de espelhar, por vezes, o nosso olhar e nos engolfar nele, tira-nos a liberdade de encontrar na diferença o único caminho de reconhecimento que nos devolve também a estranheza necessária do olhar de outros e outras. Não se pode esquecer jamais a contribuição de Carl Rogers (1976), que o mais singular e diferente em nós, também é o mais universal. Olhares estranhos nos provocam e permitem melhor nos compreender como mistérios de relação, abertos, inconclusos e, que nos devolvam a liberdade de saber que a abrangência do nosso olhar desafiado por alteridades nos levam sempre muito mais longe, do que o espelhamento narcísico que nos cativa, prende e mata.

Como se pode compreender na belíssima poesia e música "Alma Mía" da mexicana María Grever cujo texto nos fazem entrar no nosso olhar que embebeda e se empantana na busca no outro/a que termine, reincidentemente, marcar uma luta contra o narcisismo, empantanando-nos em nós próprios.

Si yo encontrara un alma como la mía, cuantas cosas secretas le contaría,

un alma que al mirarme sin decir nada me lo dijese todo con su mirada.

Un alma que embriagase con suave aliento, que al besarme sintiera lo que yo siento, y a veces me pregunto qué pasaría si yo encontrara un alma como la mía. María Grever (LAFOURCADE, 2018) ${ }^{15}$.

Não haverá jamais uma perspectiva dos muitos mundos com os quais conviveremos que nos corresponda. Sempre, todavia, haverá entre nós portas de passagens: não somos uma mônada leibniziana ${ }^{16}$, sem portas e sem janelas que jamais interditem, por natureza, viajarmos nos outros corpos até quando distemos a lonjuras planetárias, para compartilharmos vivências, saberes e, sobretudo, gerar aquilo que nos

\footnotetext{
${ }^{14}$ Jung Mo Sung menciona que denuncia Hinkelammert (1983), que em face do neoliberalismo, impingir a condição de miséria, pobreza, silenciamento de sua condição humana que lhe foi roubada, o GRITO, é o mais eficaz meio, de regenerar o sentido de luta e emancipação (SUNG, 2000).

${ }^{15}$ Interpretada por Natalia Lafourcade: $\mathrm{https://youtu.be/zZGF3vRDyIE.}$

16 "A Mônada [...] é apenas uma substância simples que entra nos compostos. Simples, quer dizer: sem partes. [...] As Mônadas não têm janelas por onde qualquer coisa possa entrar ou sair" (LEIBNIZ,1983, p. 105).
} 
é mais original de nascedouro, nossa absoluta fraternidade/sororidade que sonhamos que nos leve à amorização universal sonhada por Freire e Merleau-Ponty.

Trata-se do que é o mais íntimo do nosso íntimo: diz toda a física, química quântica, nada nos aparta da nossa coincidência no universo. Trazemos a massa do universo que se espraia na dimensão da recriação a cada segundo, em tempos inéditos, em espaços fugidios, que nos entrelaçam ${ }^{17}$ sem qualquer distância e, nos provocam ao sonho comum, de superar a diferença, que nos aproxima e poderá também nos separar, pela recusa. O certo: somos uma obra aberta, que jamais terá conclusão ou fim. Posto que aquilo que nos é mais universal é que somos um único exemplar de uma espécie genérica inextinguível! A vida nasce para viver. A morte não é o fim.

Não é no pensar - que tanto valor lhe foi dado pela Filosofia e mora na linguagem corriqueira e atrapalha reconhecer a instância primeira, a do corpo próprio, onde residem nossas identidades: a um só tempo singulares, nas múltiplas cirandas: também nos fazem universais. O "em-si-mesmamento" nos conduz à solidão. Nascidos em um solo de ambiguidades particular-universal, somos; todavia, completamente abandonados por nossas diferenças em uma solidão refletida na música "Alma Mía". Todos e todas acalentamos um desejo inútil de tomar $\operatorname{dos}($ as) outros(as) uma perspectiva radical, que jamais existirá, que nos reconciliem em tudo, e com todos e todas. Redizemos, o que é mais universal em nós é nossa singularidade, todos e todas encontrar-se-ão quando todas as diferenças fazerem cair a débil membrana que nos tira a visão imaginária dos olhos que nos mentem, veremos que a soma dos olhares de todos e todas, nos brindam com uma perspectiva de conjunto, se acolhidas, cuja plenitude das criaturas pudesse compartilhar. Utopia que por vezes acontece de uma comunhão absoluta com uma verdade ou um amor.

Nosso lugar jamais será ocupado por qualquer outro ser do mundo se o eu próprio não estiver todinho lá. Isso também inspira a ética de $\mathrm{Kant}^{18}$. Seu lugar de maior brilhantismo. E saber que Freire e Merleau-Ponty retomam a educação ética de Kant. Não somos assessórios ou dispensáveis. Não são as intensões, nem os atos de desejo, nem conhecimentos abstratos que nos representarão, será nossa carnalidade, o tecido universal que empresta o barro, o húmus, de cada corpo próprio, como princípio ontológico do meu nascimento no mundo. E é do corpo - todo de experiências feito que emergirá uma humanidade que se reconheça na diferença, sua comunhão e identidade comum; por ter podido nós próprios aceitarmos nossos limites como possibilidade de saberes, por causa disso, mais universais.

Não somos seres exclusivamente exteriores ou interiores, somos na contradição ambos ao mesmo tempo, estamos condenados ao contexto do mundo e com outrem, e, somente por isso, carregamos em nós a ambiguidade - até o fim. Ambiguidade é palavra-chave da filosofia de Merleau-Ponty: "O interior e o exterior são inseparáveis. O mundo está inteiro dentro de mim e eu estou inteiro fora de mim" (MERLEAUPONTY, 2006, p. 126). O amplexo entre eu-outro-mundo mostra que o limite de um é também sua grandeza.

Não somos criadores das bases profundas que mantém o universo. Há uma instância nas quais as nossas verdades podem ser completamente inúteis. Não poderemos, mesmo na crise, afirmar que: vamos terminar com a história. Lembrar sempre, não somos deuses, e há uma condição humana que deve ser lembrada, diuturnamente (ARENDT, 2007). Ela se faz muito além dos âmbitos das ciências e tecnologias, e por isso, as respostas da Terra desmentem o nosso pretendido e imenso

\footnotetext{
${ }^{17}$ Termo de Merleau-Ponty (2009): quiasma.

18 "Em nossa alma há qualquer coisa que chamamos de interesse: 1. por nós próprios; 2. por aqueles que conosco cresceram; e, por fim, 3. pelo bem universal" (KANT, 1999, p. 106).
} 
poder de controle, ao contrário, sejamos honestos: estamos cercados por uma ciência tão prepotente, que pela pressa, inventando saídas inconsequentes, idênticas em natureza ao que se faz para estancar sangria desatada, formulam-se intervenções paramédicas sustentadas por dogmas científicos, superficiais, localizados e linearizados computacionalmente para terem respostas comparativas.

O que se faz, nas ciências das chamadas precisões, é linearizar, superficialmente medições linearizadas de fenômenos complexos e globais. Tratar o complexo por linearização faz parte da delinquência avisada por Rubem Alves (1990) que o cientista é um sujeito perigoso, sobretudo quando interesses políticos e econômicos sustentam a eficácia e a pressa.

Não nos parece possível ler Freire fora do imenso arco do enredo de seus sonhos, perdas, sacrifícios e amores, de seu corpo. A qualidade quente e doce de sua fala, penetra fundo e acaricia à distância neste mundo, preservou em si a natureza, é trabalho duro mantido pela esperança de que sempre há jeito de avinhar os desejos da terra... Menino, não tinha caderno e livro, escola, aprendia à sombra de uma mangueira (FREIRE, 1995) - na TERRA - com uma varinha que não a ferisse, feita de cócegas e algum carinho - feliz com a comunhão do mundo para o corpo franzino! O discurso e a fala, pelas verdades que dizia, eram setas certeiras, inexoráveis. Atocaiava a superficialidade e o formalismo. Receita? Quiçá, ter o corpo inteirinho lá onde estava também a sua sombra, sem fissuras.

Verificar, escrupulosamente, o sentido etimológico de termo, cada verdade, a partir de onde ela punha os pés, para ser assim, tão tentadora. Não se trata de dominar o mundo com conceitos ou pré-conceitos. A vida acumula vivências, pelo tombo, pela cara batida em parede, pelo arrependimento da palavra, pela omissão, pelas descobertas, assombros, arrependimentos e sentidos amortizados... As perdas valem mais que tudo por nos dizerem que poderia ter sido completamente diferente, ainda assim, que a gente não deixe de exprimir, sem medo, uma modesta opinião compartilhada da verdade que emerge da alegria e dor de certo olhar viciado. A verdade sempre peregrina: se prendêla, estiola e murcha. Não vale sermos senhores e senhoras das certezas das coisas. Elas são melhores que nós. É bom ouvir e acolher toda verdade provisória que nos espante, ela não emergiu no mundo por acaso. Afinal... Somos - disse Raul Seixas: metamorfoses ambulantes ${ }^{19}$ !

Freire era todo-ouvidos, silêncio afável, cujos olhos dardejavam os nossos. Cansados de guerra, mas em repouso atento, sempre olhavam o interior e liam desejos; e, iam mais longe de onde apontávamos. Nunca dormia sobre certezas: dialéticos, acalentavam contradições. Estava aberto até o fim para o inesperado, - igualzinho à hiper-dialética $^{20}$ de Merleau-Ponty (MERLEAU-PONTY, 2009). O resultado de tudo que se tem, será uma esperança menina, verdinha e solta, sempre alargando horizontes quando parecia não haver mais nenhum. Em África, as pessoas com fome de liberdade e autonomia, às vezes, com a mesma pressa que tinham ido, voltavam no caminho. Ele sentia fundo, e esperava.

\footnotetext{
19 "Eu prefiro ser essa metamorfose ambulante; Do que ter aquela velha opinião formada sobre tudo" (SEIXAS, 1973).

${ }^{20}$ Importante entender este conceito de maneira pormenorizada para compreender uma dialética que pode ser "completamente dialética" não pode ser mantida pela supressão do polo de contradição. A dialética sempre volta, reiterada e curiosa, a manifestar tensões de dois polos de contradição, de sua diferença, de forma que ao mesmo tempo há uma reciclagem - usando uma redundância como figura de linguagem, obviamente cíclica! - pois a negação é uma afirmação negada, mas por isso mesmo é ao mesmo tempo negação-afirmada. O contrário é real. A afirmação da negação é uma afirmação. Ou seja: uma coisa negada é simultaneamente, também afirma sua negação. Jamais a destrói, apenas recicla que a natureza não funciona sob mitos de podemos desfazer o que não queremos.
} 
É preciso saber que todo caminho nos provoca. Resta-nos, a cada pessoa, lendo Freire pelo espelho de Merleau-Ponty, perceber que ambos viam o que talvez, para olhos cheios de certezas não veriam: há muitos pontos e promessas nos enviesamentos do olhar. Pelas medidas do nosso desejo, a trilha dos nossos mártires, o sonho de autonomia e emancipação, e da luta: é preciso apostar contra todas as formas de escravidão e subjugação. Dar-se conta das violências e, contra elas lutar, com todas as formas para garantir e ampliar as condições de autonomia, de liberdade, de participação.

Merleau-Ponty "Com a eclosão da guerra, serve o exército francês como oficial de infantaria" (DI CLEMENTE, 2014) ${ }^{21}$. E sua amargura era sentir que as privações, incertezas e medo, acabavam por se materializar nos seus corpos, acendendo um ódio pelo outro humano, também vítima, em uma batalha de vida e morte. Como era possível que pudéssemos desenvolver dentro de nós, um ódio, pelo outro humano, semelhante nosso, vítima como nós em uma batalha de vida e morte, na qual nos foi ensinado matálo antes? E, é aí que entra a palavra, o dizer que exige que prestemos conta da nossa missão de educadores.

Esse é o sonho que se constitui na aspiração corporal de um projeto revolucionário de transformação para a cidadania plena por Justiça e Libertação. Toda a expressão de cidadania se esteia na leitura do mundo, e na criatividade da Palavração.

Da palavra que fundava toda a pedagogia e metodologia de Freire, ele dissera:

\begin{abstract}
Verbo encarnado, Verdade Ele mesmo, a palavra que d'Ele emanava não poderia ser uma palavra que, dita, dela se dissesse que foi, mas uma Palavra que sempre estaria sendo. Esta Palavra jamais poderia ser aprendida se não fosse apreendida e não seria apreendida se não fosse igualmente por nós "encarnada". Daí o convite que Cristo nos fez e por que nos fez continua a nos fazer - o de conhecer a verdade de Sua mensagem na prática de seus mais mínimos pormenores. Sua palavra não é som que voa: é PALAVRAÇÃO (FREIRE, 1979, p. 7).
\end{abstract}

Toda palavrAção é convocatória! Ela foi o começo de tudo. Estará o tempo todo, na corporeificação dela, sendo a primeira e derradeira $p-a-l-a-v-r-a$, aquela que diz $e$ $f a z$, e refaz o que diz, cuja interioridade é publicizadora mesmo sob gritante silêncio.

Diz, na bela poesia "A Palavra Mágica" de Carlos Drummond, que ela sobrevive ${ }^{22}$ à busca.

Certa palavra dorme na sombra de um livro raro. Como desencantá-la? É a senha da vida a senha do mundo. Vou procurá-la.

Vou procurá-la a vida inteira no mundo todo.

\footnotetext{
${ }^{21}$ Entre 1939 e 1940 Merleau-Ponty foi mobilizado para a $2^{\text {a }}$ Guerra Mundial, tendo posteriormente participado da resistência contra a ocupação nazista, junto com Jean-Paul Sartre.

${ }^{22}$ Também para nós, "Paulo Freire, vive!": canto gravado em 2020, no campus do Agreste da Universidade Federal de Pernambuco (UFPE), em um piano de hotel. Música e texto realizados por Luiz Augusto Passos e Lindbergh Pires, em 1973, no Colégio Máximo Cristo Rei, em São Leopoldo (RS). Lindbergh Pires era piauiense, Irmão Jesuíta, músico, compositor e cantor. Hoje, na UFPE há um Madrigal do qual Lindbergh era o coração, que leva seu nome. Intérprete: Luiz Augusto Passos. Disponível em: https://www.youtube.com/watch?v=niBPGDZDDQA. 2021: 100 Anos - Aniversário de Paulo Freire!
} 
Se tarda o encontro, se não a encontro, não desanimo, procuro sempre.

Procuro sempre, e minha procura ficará sendo minha palavra.

(ANDRADE, 2014, p. 127).

\section{REFERÊNCIAS}

ALVES, R. Filosofia da ciência: introdução ao jogo e suas regras. 13. ed. São Paulo: Brasiliense, 1990.

ANDRADE, C. D. A palavra mágica. In: ANDRADE, C. D. Discurso de primavera e algumas sombras. São Paulo: Companhia das Letras, 2014. p. 127.

ARENDT, H. A condição humana. 10 ed. 6. reimp. Rio de Janeiro: Forense Universitária, 2007.

BARROS, M. O menino que carregava água na peneira. In: BARROS, M. Poesia completa. São Paulo: Leya, 2010. p. 469-470.

BOFF, L. Leonardoboff.com. Disponível em: https://leonardoboff.org/. Acesso em: 11 abr. 2020.

CAMUS, A. L’ Etranger. Paris: Gallimard, 1967.

CHAUÍ, M. Da realidade sem mistérios ao mistério do mundo: Espinosa, Voltaire, Merleau-Ponty. São Paulo: Brasiliense, 1981.

DI CLEMENTE, F. Biografia do filósofo. Portal do GPMSE/GEMPO: Estudos Educação e MerleauPonty, 28 out. 2011. Disponível em: http://gempo.com.br/portal/biografia-do-filosofo/. Acesso em: 11 abr. 2020.

FIRENZE, A. Invariante biológico e natureza humana. Notas críticas sobre o uso da antropologia filosófica em Virno. Revista de Educação Pública, v. 23, n. 53/2, p. 533-552, jul. 2014.

FREIRE, A. M. A. Paulo Freire: uma história de vida. Indaiatuba: Vila das Letras, 2006.

FREIRE, P. Pedagogia da tolerância. São Paulo: Editora UNESP, 2005.

FREIRE, P. À sombra desta mangueira. São Paulo: Olho d'Água, 1995.

FREIRE, P. Pedagogia do oprimido. Rio de Janeiro: Paz e Terra, 1983.

FREIRE, P. Conhecer, praticar, ensinar os Evangelhos. Tempo e Presença, n. 154, p. 7, out. 1979. Disponível em: http://acervo.paulofreire.org:8080/jspui/bitstream/7891/2325/3/FPF_OPF_07_003.pdf. Acesso em: 11 abr. 2020.

FREUD, S. Totem e tabu; ensaios. Coleção “Obras Completas de Sigmund Freud”, v. 14. Rio de Janeiro: Editora Delta, 1950.

HINKELAMMERT, F. J. As armas ideológicas da morte. São Paulo: Paulinas, 1983.

KANT, I. Sobre a pedagogia. 2. ed. rev. Piracicaba: Editora Unimep, 1999.

LAFOURCADE, N. Musas: un homenaje al folclore latinoamericano en manos de los macorinos, v. 2. Sony Music, 2018. 1 CD.

LEIBNIZ, G. W. A monadologia. Coleção “Os Pensadores”. 2. ed. São Paulo: Abril Cultural, 1983. 
Armando de Melo Lisboa; Luiz Augusto Passos

MELIÀ, B. ¡Ay del que enseña a leer al que no sabe! Acción, Asunción, n. 14, 1972. Disponível em: http://www.mondialisations.org/medias/pdf/Ay-del-que-ensena-a-leer.pdf. Acesso em: 11 abr. 2020.

MERLEAU-PONTY, M. O visível e o invisível. São Paulo: Perspectiva, 2009.

MERLEAU-PONTY, M. Fenomenologia da percepção. 3. ed. São Paulo: Martins Fontes, 2006.

MOUNIER, E. O personalismo. Lisboa: Martins Fontes, 1973.

PAULO Freire - Dia do Meio Ambiente - 5 de junho. Publicado pelo canal Instituto Paulo Freire em jun. 2015. 1 vídeo (22 seg.). Disponível em: https://www.youtube.com/watch?v=J170pf5e5No. Acesso em: 11 abr. 2020 .

ROGERS, C. Tornar-se pessoa. São Paulo: Martins Fontes, 1976.

SEIXAS, R. Metamorfose ambulante. In: SEIXAS, R. Krig-ha, Bandolo! Philips Records, 1973. 1 LP.

SEMINÁRIO Internacional "O Simbólico e o Diabólico, Dramas e Tramas, Religião, História e Política". Teatro da Universidade Católica de São Paulo (TUCA), set. 1996. 1 vídeo (64 min.). Publicado pelo canal TV PUC. Disponível em: https://www.youtube.com/watch?v=Me7yEtvctog. Acesso em: 11 abr. 2020.

SUNG, J. M. Sujeito como transcendentalidade ao interior da vida real: um diálogo com o pensamento de Franz Hinkelammert. Cadernos do IFAN, Bragança Paulista, n. 26, p. 47-66, 2000.

Recebido em: 11 abr. 2020.

Aprovado em: 29 abr. 2020. 